\title{
Grain Boundary Segregation of Rare-Earth Elements in Magnesium Alloys
}

\begin{abstract}
JOSEPH D. ROBSON, SARAH J. HAIGH, BRUCE DAVIS, and DAVID GRIFFITHS
Small additions of rare-earth (RE) elements have been shown to have a powerful effect in modifying the texture of wrought magnesium alloys, giving a highly beneficial effect in improving their formability. Recent work has shown that segregation of RE atoms to grain boundaries is important in producing this texture change. In this work, two $\mathrm{Mg}-\mathrm{RE}$ systems have been studied $\mathrm{Mg}-\mathrm{Y}$ and $\mathrm{Mg}-\mathrm{Nd}$ using high-resolution scanning transmission electron microscopy that permits both imaging and elemental analysis with a spatial resolution of better than $0.1 \mathrm{~nm}$. The $\mathrm{Mg}-\mathrm{Y}$ alloy, where the solubility and level of addition are relatively high, showed the RE texture change effect. This was accompanied by clustering of $\mathrm{Y}$ on the grain boundaries, consistent with previous studies of the Mg-Gd system. The Mg-Nd alloy, where the solubility and level of addition are relatively low, showed no texture change and no segregation. In this case, impurity elements binding the RE into insoluble particles, rendering it ineffective. The results are analyzed by modifying a previous model for the solute drag effect on boundaries expected due to the RE additions. This predicts that both Gd and Y will strongly inhibit boundary motion, with Gd being approximately twice as effective as Y.
\end{abstract}

DOI: $10.1007 / \mathrm{s} 11661-015-3199-3$

(C) The Author(s) 2015. This article is published with open access at Springerlink.com

\section{INTRODUCTION}

A key limitation of current wrought magnesium alloy sheet is poor cold formability. ${ }^{[1]}$ It has been demonstrated that the strong basal textures that characterize conventional magnesium alloy sheets is a major contributing factor to this poor formability. ${ }^{[2,3]}$ Small additions of rare-earth (RE) elements have been shown to modify the texture of magnesium sheet after hot rolling, producing weaker texture and an increased split in basal pole orientations. Sheets produced from alloys with these modified textures show significantly improved formability compared to conventional magnesium alloy sheets with a strong basal texture. ${ }^{[2]}$

It is now known that the amount of RE needed to activate texture change can be very small. ${ }^{[2-5]}$ For example, for low-solubility REs such as Ce, only 0.03 at. pct addition is required to produce a strong texture weakening effect. ${ }^{[3]}$ This observation has led to the suggestion that segregation is likely to be important in enabling much higher concentrations to be achieved locally at sites such as grain boundaries and dislocations. ${ }^{[6-9]}$

The critical RE concentration required to change the texture has been observed to vary directly with the solubility of the element, i.e., for elements with a higher solubility, more RE is needed. ${ }^{[10]}$ However, it has been concluded that this transition is not associated with

JOSEPH D. ROBSON, Professor, SARAH J. HAIGH, Reader, and DAVID GRIFFITHS, Research Student, are with the School of Materials, University of Manchester, MSS Tower, Manchester M13 9PL, UK. Contact e-mail: joseph.robson@manchester.ac.uk BRUCE DAVIS, Research Manager, is with Magnesium Elektron North America, 1001 College St., P.O. Box 258, Madison, IL 62060.

Manuscript submitted April 23, 2015.

Article published online October 19, 2015 precipitation, since the critical RE concentration required to produce the texture weakening effect is below the solid solubility. ${ }^{[5,10]}$ A detailed description of the RE texture weakening effect and proposed mechanisms are reviewed elsewhere. ${ }^{[1]}$ One important factor that has been widely reported is an effect of RE additions in suppressing dynamic recrystallization (DRX). This appears to be critical in enabling a deformed structure to be obtained containing a wider spread of orientations, deformation heterogeneities, and higher stored energy. ${ }^{\left[{ }^{3}\right]}$ When these structures recrystallize, a weaker texture is obtained. Segregation of RE to grain boundaries would be expected to provide a strong drag force suppressing DRX. The predictions of simple classical models for boundary segregation and solute drag support this hypothesis. ${ }^{[12]}$

There is now direct experimental evidence that RE elements can segregate strongly to grain boundaries. These data have been obtained using both atom probe ${ }^{[6]}$ and high-resolution transmission electron microscopy (HRTEM) ${ }^{[7-9]}$ A recent investigation ${ }^{[8]}$ of two Mg-Gd alloys using high-angle annular dark-field (HAADF) scanning transmission electron microscope (STEM) imaging has revealed that the RE atoms can segregate into small clusters at grain boundaries. It was demonstrated that the texture associated with the RE effect in extruded material was only observed in an alloy that contained sufficient $\mathrm{Gd}(0.06$ at. pct) to produce clearly detectable boundary segregation. In an alloy with a very low level of $\mathrm{Gd}$ (0.01 at. pct), no grain boundary segregation was observed and no RE texture was produced. Bugnet et al..$^{[9]}$ have studied the segregation of $\mathrm{Gd}$ at grain boundaries in $\mathrm{Mg}$ in detail. They have shown that there is a high level of enrichment, with clusters apparently of a cubic phase of Gd located at the 
boundary. Interestingly, they have suggested that the clusters consist of pure Gd and are not an intermetallic compound as might be expected from the phase diagram.

In this study, two other important RE additions are investigated: $\mathrm{Y}$ and $\mathrm{Nd}$. $\mathrm{Y}$ is an important element in current commercial magnesium alloys, such as WE43, where it is added in relatively high concentrations mainly to produce creep-resistant age-hardening precipitates rather than to produce a texture change. Nevertheless, the RE texture effect in a byproduct of this addition. $\mathrm{Y}$ is a relatively high-solubility $\mathrm{RE}$, being capable of dissolving in $\mathrm{Mg}$ up to 3 at. pet at $673 \mathrm{~K}\left(400{ }^{\circ} \mathrm{C}\right)$. It has a similar solubility and predicted tendency to segregate to $\mathrm{Gd}$, which has been studied in more detail previously. One aim of this study was to determine whether the segregation features observed in Mg-Gd alloys are typical of those found in other Mg-RE systems with high RE solubility.

$\mathrm{Nd}$ is a low-solubility RE [0.4 at. pet at $673 \mathrm{~K}$ $\left.\left(400{ }^{\circ} \mathrm{C}\right)\right]$. It has been shown previously that it can produce a texture change in $\mathrm{Mg}$ even when added at a level of only 0.04 at. pct. ${ }^{[10]}$ There is a great interest in finding RE additions that can be added in very low concentrations to produce a texture change since RE additions are expensive.

Previously, Robson ${ }^{[12]}$ has demonstrated that a simple classical grain boundary segregation and solute drag model (the Cahn-Lücke-Stüwe model ${ }^{[13,14]}$ ) can be used to estimate the tendency for RE elements to segregate to boundaries and the drag pressure they will produce. This model is based on the assumption that it is the misfit between the RE atoms (which are large) relative to the matrix $\mathrm{Mg}$ atoms that provides the driving force for boundary segregation.

The ability to provide a semi-quantitative measurement of the grain boundary composition using the TITAN G2 80-200 ChemiSTEM employed in this study has allowed these predictions to be revisited and revised. With this information, a more accurate assessment of the likely drag effect of different RE additions can be made and thus their effect on phenomena that require boundary migration including recrystallization and grain growth.

\section{EXPERIMENTAL}

The Mg-Y and Mg-Nd alloys were cast by Magnesium Elektron into rectangular steel molds, homogenized at $823 \mathrm{~K}\left(550{ }^{\circ} \mathrm{C}\right)$, and hot rolled at $673 \mathrm{~K}$ $\left(400{ }^{\circ} \mathrm{C}\right.$ ) to a reduction of 1.4 (true strain) in seven equal passes. Annealing was performed following rolling for 1 hour at $673 \mathrm{~K}\left(400^{\circ} \mathrm{C}\right)$ to produce a recrystallized microstructure.

The alloys were nominally binaries that contained either 0.15 at. pet $\mathrm{Y}$ or 0.024 at. pct $\mathrm{Nd}$ (determined by inductively coupled plasma optical emission spectroscopy, ICP-OES). Both of these concentrations are well below the expected solubility limits at the rolling and annealing temperatures but are above the critical concentration expected to activate the RE texture weakening effect. ${ }^{[3]}$ As with most other studies on Mg-RE alloys, high-purity feedstock was not used, so small amounts of other elements (mainly $\mathrm{Fe}$ ) are also present in the alloys. The iron level is a maximum of 0.004 at. pct. The texture of these alloys was compared to that of an $\mathrm{Mg}-0.009$ at. pct $\mathrm{Y}$ alloy prepared in the same way and with a similar maximum iron level. The Y in this alloy is present as an impurity and is well below the critical threshold required to activate the RE texture effect. ${ }^{[3]}$

The textures of the as-rolled and annealed material were measured by X-ray diffraction using a Bruker D8 Discover diffractometer. Samples were ground and polished to remove the deformed surface layer prior to texture measurement. $\{10 \overline{1} 0\},\{0002\},\{10 \overline{1} 1\}$, and $\{10 \overline{1} 2\}$ pole figures were measured. After background and defocusing corrections were applied, the pole figures were combined to generate an orientation distribution function (ODF) using the MTEX texture analysis package, from which the recalculated pole figures presented here were computed.

Specimens of annealed material were prepared for transmission electron microscope imaging using standard metallographic procedures followed by dimple grinding to $20 \mu \mathrm{m}$ thickness and precision ion polishing for approximately 20 hours to produce a hole, using a $6 \mathrm{deg}$ incidence angle and $4 \mathrm{kV}$ Ar ion beams. Brightfield and HAADF STEM imaging were performed using the Titan G2 80-200 ChemiSTEM operated with an accelerating voltage of $200 \mathrm{kV}$, a probe current of $500 \mathrm{pA}$, a convergence semi-angle of $21 \mathrm{mradn}$ and an HAADF inner semi-angle of $54 \mathrm{mrad}$. The instrument is equipped with a high-brightness X-FEG electron source and four silicon drift energy-dispersive X-ray (EDX) detectors (total EDX collection angle $=0.7$ srad) enabling imaging and elemental analysis to be performed with a spatial resolution of better than $0.1 \mathrm{~nm}$.

EDX spectrum images were acquired using all four EDX detectors, a pixel dwell time of $30 \mu$ s and a total acquisition time of 2 to 10 minutes. Quantification was performed using an absorption-corrected Cliff-Lorimer approach within the Bruker Esprit software assuming a specimen thickness of 100 to $200 \mathrm{~nm}$. Care was taken to align the sample so that grain boundaries were parallel to the incoming electron beam in order to prevent smearing of the projected compositional profiles, but the accuracy of this correction was limited to 1 to $2 \mathrm{deg}$ (giving a broadening of $1 \mathrm{~nm}$ for an estimated sample thickness of $100 \mathrm{~nm}$ ).

\section{MODEL}

The Cahn-Lücke-Stüwe (CLS) ${ }^{[13,14]}$ model for solute drag on grain boundaries has been described in detail elsewhere, and its application to predicting drag for Mg-RE binaries was detailed in a previous publication. ${ }^{[12]}$ This model assumes that there is a free energy advantage for solute atoms to lie in the grain boundary region. An additional pressure is required on the boundary to overcome this attraction. The drag effect 
depends on the depth of the free energy well associated with solute located on the grain boundary, the diffusivity of the solute species, and the boundary velocity. The CLS model predicts that there are two drag pressure regimes as a function of boundary velocity; in the low-velocity regime, drag increases as boundary velocity increases and in the high-velocity regime drag pressure decreases with increasing boundary velocity. The maximum drag effect occurs at the transition between the regimes.

The physical interpretation of this transition is the change from a regime where an enriched solute region can be dragged along with the boundary (low velocity) to a regime where the boundary breaks away from the solute-enriched region. Cahn demonstrated that in the low-velocity limit, slower diffusing solutes will lead to greater drag, whereas in the high-velocity limit the opposite is true. ${ }^{[13]}$ It was shown previously that for $\mathrm{Y}$ in $\mathrm{Mg}$, and for boundary velocities typical of those expected during recrystallization, the drag pressure is close to its peak value and near the transition from the high- to low-velocity regimes. ${ }^{[12]}$ For other typical additions to $\mathrm{Mg}$ (e.g., $\mathrm{Al}$ and $\mathrm{Zn}$ ), it was also shown that the predicted drag pressure is several orders of magnitude smaller and is well within the low-velocity regime.

In the classical implementation of the CLS model, as described for Mg-RE alloys in Reference 12, it is assumed that the free energy advantage associated with solute locating on the grain boundaries is mainly due to a relaxation of the elastic misfit strain energy associated with the solute dissolved in the matrix. However, the CLS model does not prescribe this as the only effect that can cause solute drag. Other contributions to the free energy change at boundaries come from the chemical effect. In previous application of the CLS model to solute drag in the Mg-Y system, the classical (elastic only) assumption was used to calculate the free energy change associated with solute locating on the grain boundaries. However, as shown later, the equilibrium boundary solute content predicted using this assumption is a significant underestimate of the boundary concentration measured in the present work $(\simeq 6$ times too small). This suggests that the segregation of RE solute to the boundaries is not only driven by atom size with the magnesium matrix, but there is also a significant chemical component as well as an interaction between the RE and minor impurities present in the alloy that also segregate to the boundaries (as demonstrated later).

In the present work, the measured $\mathrm{Y}$ content on the boundary has been used to estimate the true depth of the free energy well at grain boundaries, $\Delta G_{\text {seg. }}{ }^{[15]}$ This will implicitly include interaction and chemical effects that also contribute to the free energy well, in addition to the relief of elastic misfit strain.

$$
\Delta G_{\mathrm{seg}}=k T \ln \frac{X_{\mathrm{GB}}}{X_{\mathrm{M}}},
$$

where $X_{\mathrm{GB}}$ is the (measured) maximum solute concentration on the grain boundary, $X_{\mathrm{M}}$ is the average solute concentration, and $k$ and $T$ have their usual meanings.
Using the revised value of $\Delta G_{\text {seg }}$ calculated from measurement, the CLS model can be applied to predict the solute drag associated with Y segregation.

According to the CLS model, the drag pressure due to solute is given by ${ }^{[13]}$

$$
P_{\mathrm{d}}=\frac{\alpha v X_{\mathrm{M}}}{1+\beta^{2} v^{2}},
$$

where $v$ is the boundary velocity and $\alpha$ and $\beta$ are parameters that depend on the diffusion and free energy profiles assumed in the vicinity of the grain boundary (see Robson ${ }^{[12]}$ for details), which are obtained from ${ }^{[16]}$ as

$$
\begin{gathered}
a=\frac{\mathrm{RT}}{\delta G_{\mathrm{seg}}} \log \left(\frac{D}{D_{\mathrm{GB}}}\right), \\
\alpha=\frac{4 R^{2} T^{2}}{V_{\mathrm{m}} G_{\mathrm{seg}}^{2} D} \frac{1}{a^{3}-a}, \\
\frac{\alpha}{\beta^{2}}=\frac{2 G_{\mathrm{seg}} D_{\mathrm{GB}}}{V_{\mathrm{m}} a}\left(1-\frac{D}{D_{\mathrm{GB}}}\right),
\end{gathered}
$$

where $D$ is the bulk diffusion coefficient of solute, $D_{\mathrm{GB}}$ is the grain boundary diffusion coefficient, and $V_{\mathrm{m}}$ is the molar volume. For $\mathrm{Y}$ and $\mathrm{Gd}$ in $\mathrm{Mg}, D_{0}$ and $Q$ for bulk diffusion were given by Reference 17 . The anisotropy in the diffusion coefficient (which is small at the temperatures of interest here ${ }^{[17]}$ ) was ignored. There are no reported data for the impurity diffusion coefficient of $\mathrm{Ni}$ in $\mathrm{Mg}$, and so this was taken from the values reported for $\mathrm{Ni}$ in $\mathrm{Al}$; the justification for this is discussed later. Since the appropriate values for GB diffusion are not known, the commonly used approximation was made that $Q_{\mathrm{GB}} \simeq 0.5 Q .{ }^{[18]}$ These input parameters to the model are summarized in Table I

\section{RESULTS AND DISCUSSION}

\section{A. Texture Measurements and Microstructure}

Figure 1 compares the $\{0001\}$ pole figures of $\mathrm{Mg}$ (with very low $\mathrm{Y}$ ), $\mathrm{Mg}-\mathrm{Y}$, and $\mathrm{Mg}-\mathrm{Nd}$ alloys after hot rolling $(\mathrm{a}-\mathrm{c})$ and annealing $(\mathrm{d}-\mathrm{f})$. The $\mathrm{Mg}$ with negligible RE addition has the expected strong basal texture (maximum $=16$ multiples of random density, MRD) with no significant splitting of the basal poles from the normal direction. After annealing, a slight split in the basal poles toward the rolling direction (RD) is observed, but the texture remains very strong (maximum $=14$ MRD). The Mg-Y alloy shows a weaker texture (maximum $=7.3 \mathrm{MRD}$ ) with a significant split in the basal poles toward the RD in the as-rolled condition. On annealing, the texture weakens further (maximum $=4.5 \mathrm{MRD})$. The $\mathrm{Mg}-\mathrm{Nd}$ alloy shows a similar texture strength in the as-rolled condition (maximum $=8.4 \mathrm{MRD}$ ), but the texture strength in this case does not weaken significantly during annealing 
Table I. Input Parameters for the Calculation of Diffusion Coefficients Used in Model

\begin{tabular}{llll}
\hline Symbol & \multicolumn{1}{c}{ Parameter } & Value \\
\hline$D_{0}(\mathrm{Y})$ & pre-factor for Y diffusion & $3.2 \times 10^{-8} \mathrm{~m}^{2} \mathrm{~s}^{-1}$ & Source \\
$Q(\mathrm{Y})$ & activation energy for Y diffusion & $99.1 \mathrm{~kJ} \mathrm{~mol}^{-1}$ & {$[17]$} \\
$D_{0}(\mathrm{Gd})$ & pre-factor for Gd diffusion & $1.8 \times 10^{-9} \mathrm{~m}^{2} \mathrm{~s}^{-1}$ & {$[17]$} \\
$Q(\mathrm{Gd})$ & activation energy for Gd diffusion & $81.6 \mathrm{~kJ} \mathrm{~mol}^{-1}$ & $4.1 \times 10^{-4} \mathrm{~m}^{2} \mathrm{~s}^{-1}$ \\
$D_{0}(\mathrm{Ni})$ & pre-factor for Ni diffusion & $144.6 \mathrm{~kJ} \mathrm{~mol}^{-1}$ & {$[17]$} \\
$Q(\mathrm{Ni})$ & activation energy for Ni diffusion & {$[19]^{*}$} & {$[19]^{*}$} \\
\hline
\end{tabular}

*Data for Ni relate to impurity diffusion coefficient in $\mathrm{Al}$ (see text for details).

(maximum $=7.1 \mathrm{MRD}$ ) and so a strong basal texture is retained. These observations are consistent with previous work on binary Mg-RE alloys (e.g., References 2, 10).

Segregation was studied in the annealed condition. In this condition, all specimens were fully recrystallized with an approximately equiaxed grain structure. The mean grain size in the annealed state was approximately $25 \mu \mathrm{m}$ in the Mg-0.15 at. pet $\mathrm{Y}$ alloy, $50 \mu \mathrm{m}$ in the in the Mg-0.024 at. pet $\mathrm{Nd}$ alloy, and $60 \mu \mathrm{m}$ in the Mg-0.009 at. pet Y alloy.

\section{B. High-Resolution Imaging and Composition Measurement}

Figure 2 shows HAADF images in which the strong atomic number dependence of HAADF image contrast clearly reveals the presence of a high-atomic number element at the grain boundary. HAADF imaging, Figure 2, also reveals that segregation is not uniformly distributed along the boundary, but that the boundary is decorated by nanometer-sized solute clusters. Interestingly, the high-resolution HAADF image in Figure 2(b) shows that the clusters have some preferential orientation relationship with the lattice. These results are very similar to the Gd segregation observed by Hadorn et al. in their Mg-0.06 at. pet Gd alloy and Bugnet et al. in $\mathrm{Mg}-0.28$ at. pet Gd. ${ }^{[8,9]}$ This suggests that Y, a high-solubility RE in the same sub-group as $\mathrm{Gd}$, does indeed behave very similarly to $\mathrm{Gd}$ with regard to segregation. It should be noted that although the RE is observed to form clusters along the boundary, these clusters are very closely spaced and form what at low magnification appears to be a continuous layer of RE on the boundary. It is difficult to determine the cluster spacing since the depth of the clusters through the foil is not easily determined. However, both the present work and previous studies ${ }^{[7-9]}$ suggest that the clusters are so closely spaced that they will provide a uniform drag effect on the boundary, and are only a few atom diameters in size, so are therefore likely to be unstable and break up once the boundary moves away. Thus the drag effect the RE exerts is most appropriately modeled using a solute drag model (e.g., CLS model), rather than a particle pinning model (e.g., Zener pinning model ${ }^{[15]}$, where the assumption is that the particles are inert and widely spaced (relative to their size), forming a static dispersion through which the boundary can pass by bowing between particles.
EDX spectrum imaging of the grain boundary region confirms, as predicted, that $\mathrm{Y}$ is strongly segregated to the grain boundary and also reveals that impurity $\mathrm{Ni}$ segregated to the boundary (Figure 3 ). The low levels of $\mathrm{Ni}$ contamination observed are presumably introduced during the casting process, although the source remains uncertain. As shown in Figure 3(e), a line scan across the boundary can be obtained by summing pixel spectra contained in the spectrum image. This reveals a peak segregation of 2.4 at. pct Y (16 times the average alloy concentration) and 1.1 at. pct $\mathrm{Ni}$, with both elemental peaks having a full width half maximum (FWHM) of $1.4 \mathrm{~nm}$. A number of different grain boundaries were observed with different misorientations and were found to have peak Y concentrations of 1.4 to 2.5 at. pct and widths of 1 to $2 \mathrm{~nm}$. Segregation was observed on all the boundaries studied although more detailed investigation is required to determine any relationship between the level of segregation and grain boundary character. This semi-quantitative analysis supports previous qualitative work in revealing that the tendency for segregation to the grain boundaries is very strong, with at least an order of magnitude increase in local concentration along the boundary. The identification of the presence of both $\mathrm{Y}$ and $\mathrm{Ni}$ together with semi-quantitative analysis of grain boundary enrichment would be impossible without the high-brightness probe and high-efficiency EDX spectrum imaging capabilities available using the Titan.

The present results can be compared with predictions made previously with the CLS model ${ }^{[12]}$ assuming that segregation is driven by size and elasticity mismatch alone (the Langmuir MacClean (LM) model ${ }^{[20]}$ ). When this model is applied to the $\mathrm{Mg}-\mathrm{Y}$ alloy assuming all of the solute is available for segregation, the local grain boundary (GB) concentration is predicted to be 0.42 at. pct (approximately three times the bulk composition). The LM model clearly underestimates the true amount of segregation observed by a factor of approximately 6. There are two explanations for this discrepancy, and both are likely to play some role. Firstly, the LM model ignores the chemical contribution to the free energy reduction on segregation of $\mathrm{Y}$ to the grain boundaries. Secondly, the unexpected observation of enriched $\mathrm{Ni}$ on the grain boundary is likely to lead to a synergistic effect that influences $\mathrm{Y}$ segregation. Where there is an attractive interaction between two elements, the tendency to co-segregate will be increased. ${ }^{[21]}$ This attraction can be chemical or due to elastic interactions; it is noteworthy that while $\mathrm{Y}$ in solution in $\mathrm{Mg}$ is a large 


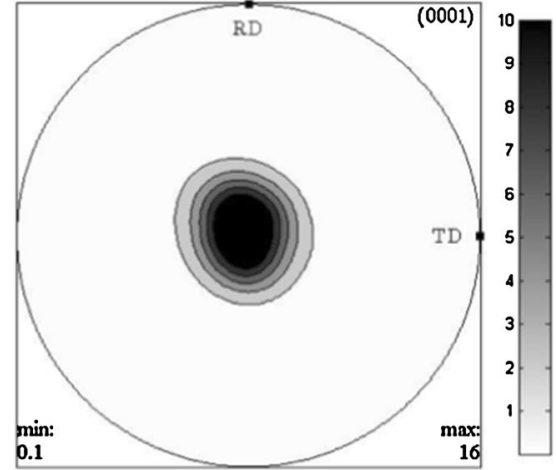

(a)

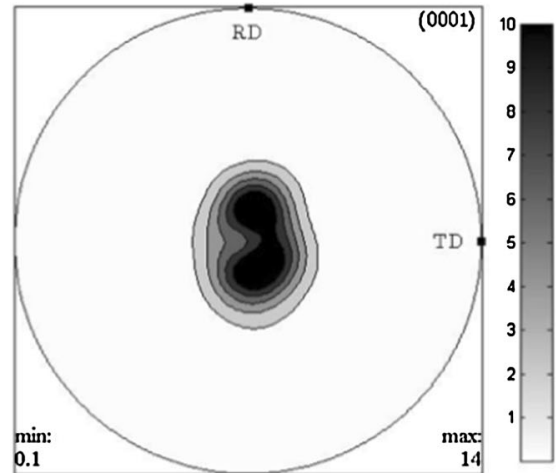

(d)

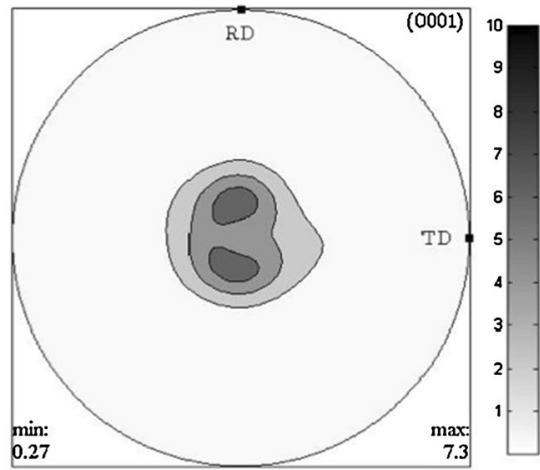

(b)

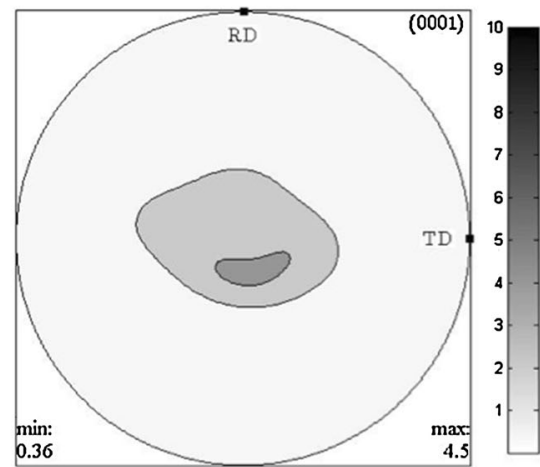

(e)

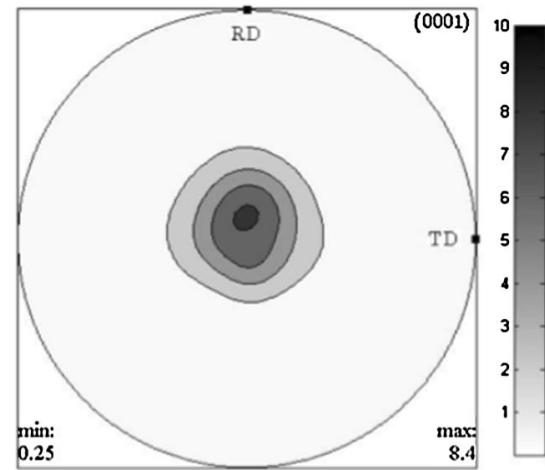

(c)

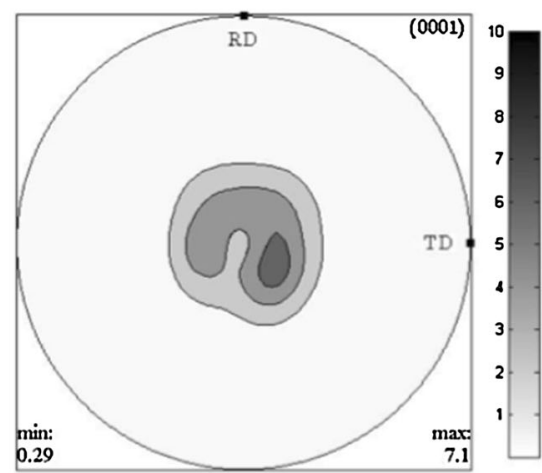

(f)

Fig. $1-$ Basal pole figures for $(a) \mathrm{Mg}-0.009$ at. pct $\mathrm{Y},(b) \mathrm{Mg}-0.15$ at. pct $\mathrm{Y},(c) \mathrm{Mg}-0.024$ at. pct $\mathrm{Nd}$, (all as-rolled), (d) Mg-0.009 at. pct $\mathrm{Y},(e)$ $\mathrm{Mg}-0.15$ at. pet $\mathrm{Y}$, and $(f) \mathrm{Mg}-0.024$ at. pet $\mathrm{Nd}$ [after annealing for $1 \mathrm{~h}$ at $673 \mathrm{~K}\left(400{ }^{\circ} \mathrm{C}\right)$ ].

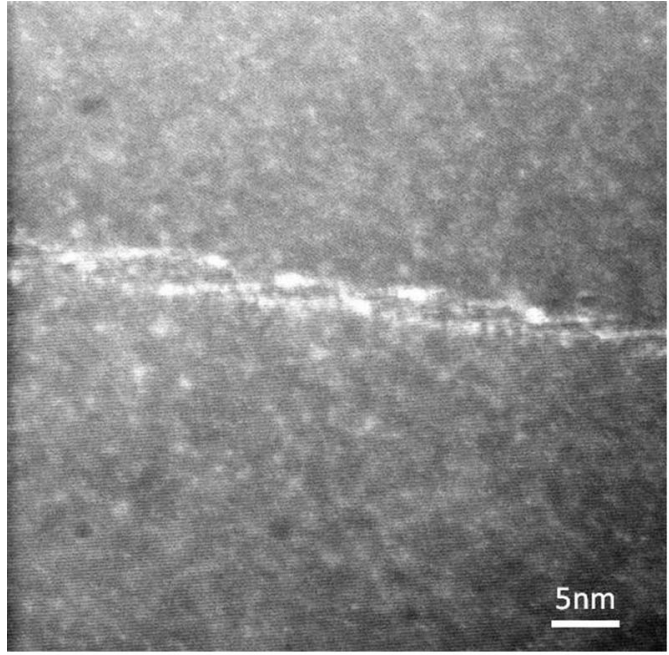

(a)

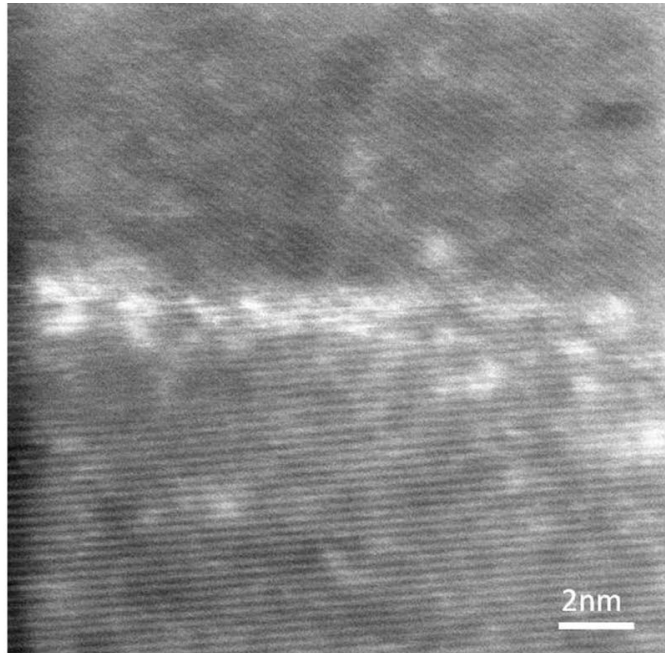

(b)

Fig. 2- HAADF STEM images showing segregation of $\mathrm{Y}$ at grain boundaries at $(a)$ low and $(b)$ higher magnification.

atom relative to $\mathrm{Mg}(\mathrm{Y} / \mathrm{Mg}$ size ratio 1.14$), \mathrm{Ni}$ is small $\left(\mathrm{Mg} / \mathrm{Ni}\right.$ size ratio 1.28). ${ }^{[22]}$ The solubility of $\mathrm{Ni}$ is $\mathrm{Mg}$ is almost zero, ${ }^{[23]}$ and there is thus a highly unfavorable enthalpy of mixing between $\mathrm{Mg}$ and $\mathrm{Ni}$. This favors rejection of $\mathrm{Ni}$ to the grain boundaries, where it is likely to have a synergistic effect with $\mathrm{Y}$ segregation (based on a size consideration alone), further enhancing the segregation of both elements. The level of impurity $\mathrm{Ni}$ in this alloy as measured by ICP-OES was only 0.002 at. pct, and the measured concentration on the boundary of 1.1 at. pct is 550 times higher, indicating a very strong energy advantage for segregation of this element in the presence of $\mathrm{Y}$.

As discussed, a key difference between the Mg-Y alloy and $\mathrm{Mg}-\mathrm{Nd}$ alloy is that the Nd-containing alloy does not show significant texture weakening during 


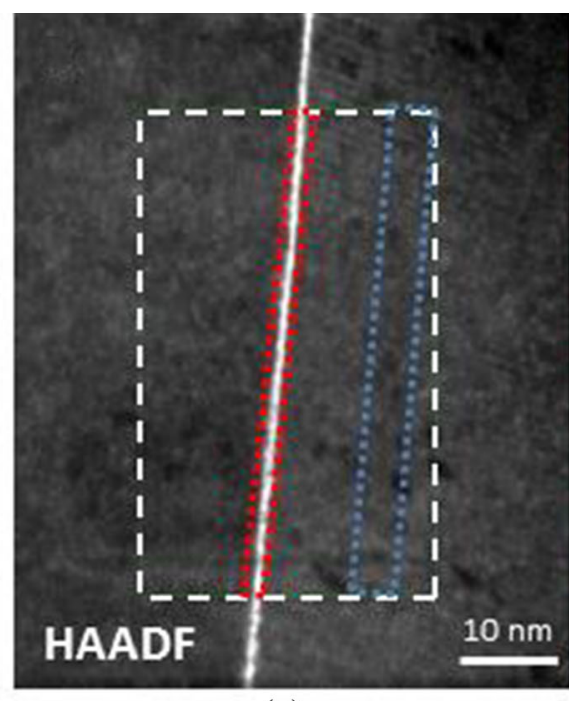

(a)

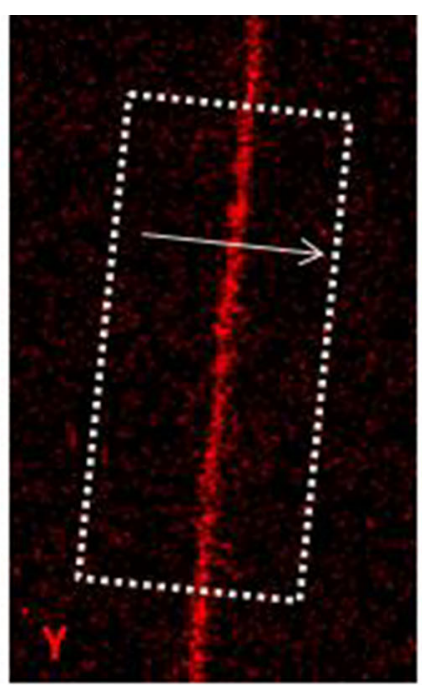

(b)

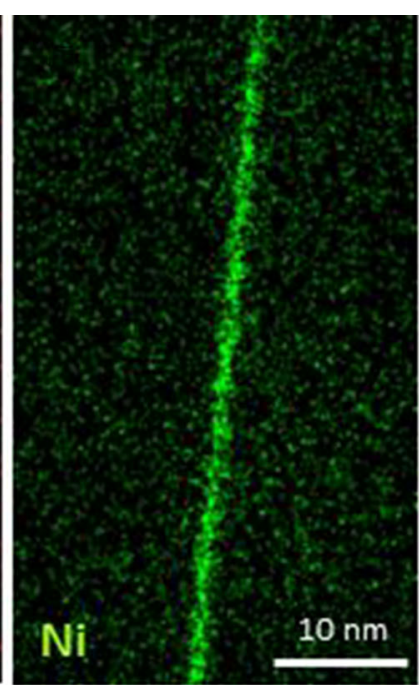

(c)

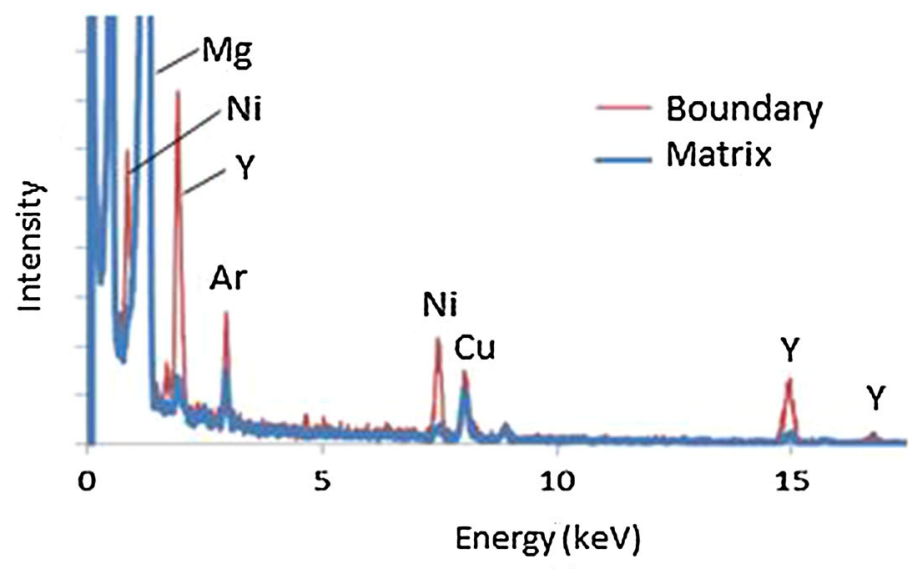

(d)

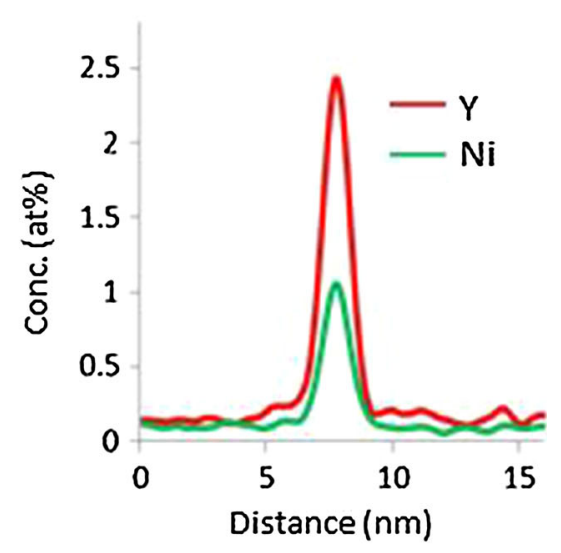

(e)

Fig. 3-Energy-dispersive X-ray spectrum imaging of grain boundary segregation. (a) HAADF STEM images showing grain boundary region. $(b, c)$ Elemental maps for $\mathrm{Y}$ and $\mathrm{Ni}$ extracted from the EDX spectrum image. (d) EDX spectra summed over the region of grain boundary and of the matrix illustrated by the red and blue dashed lines in (a). Summed spectra have been normalized to the Mg peak. The presence of Ar and $\mathrm{Cu}$ in both spectra are the result of ion polishing sample preparation and scattering from the TEM sample holder, respectively. (e) Semi-quantitative analysis showing $\mathrm{Y}$ and $\mathrm{Ni}$ enrichment at the grain boundary for the region shown by the dashed rectangle in (b).

recrystallization on annealing. A similar approach was employed to analyze grain boundaries in the $\mathrm{Mg}-\mathrm{Nd}$ alloy, but no evidence of $\mathrm{Nd}$ segregation was observed. Figure 4(a) shows an example grain boundary with the corresponding $\mathrm{Nd}$ elemental map showing no evidence of $\mathrm{Nd}$ in the grain boundary. Semi-quantitative line scans of the alloy material confirmed this observation with no detectable $\mathrm{Nd}$ observed in the summed spectra obtained from the full elemental map of the GB region. This result was initially surprising, since according to the LM model $\mathrm{Nd}$ should have an even greater tendency to segregate than Y. However, extensive STEM imaging also revealed the presence of unexpected second-phase particles within the alloy. Some of these particles can be seen close to the grain boundary in Figure 4(a), and EDX spectrum imaging revealed these to be rich only in oxygen. Clusters of larger facetted particles with sizes ranging from 20 to $>300 \mathrm{~nm}$ were also observed within the grains, and these were revealed to be primarily composed of $\mathrm{Nd}$, impurity $\mathrm{Fe}$, or a combination of both elements (Figures 4(b) through (d)). The presence of these particles, which contain impurity $\mathrm{Fe}$ and $\mathrm{Nd}$, will reduce the availability of $\mathrm{Nd}$ in the matrix.

The solubility of $\mathrm{Fe}$ in $\mathrm{Mg}$ at the annealing temperature $\left[673 \mathrm{~K}\left(400{ }^{\circ} \mathrm{C}\right)\right]$ is very low $\left(<7 \times 10^{-6}\right.$ at. $\left.\mathrm{pct}^{[24]}\right)$. Using the measured $\mathrm{Nd}: \mathrm{Fe}$ ratio (8:1) in the largest particles (Figure 4(d)) and the solubility of $\mathrm{Fe}$ in $\mathrm{Mg}$ stated previously, up to an estimated 0.032 at. pct of $\mathrm{Nd}$ could be removed into these particles (assuming iron is fully precipitated). This exceeds the level of $\mathrm{Nd}$ added to the alloy. Thus, it is conceivable that almost all of the $\mathrm{Nd}$ is locked up in insoluble particles and is not available in the matrix to segregate to boundaries.

This is an important observation since it highlights that the level of impurity elements such as $\mathrm{Fe}$ and $\mathrm{O}$ will have an effect on the critical level of $\mathrm{Nd}$ addition required to produce segregation, since there must be sufficient $\mathrm{Nd}$ retained in the matrix once the removal of some of this element into impurity particles has been 


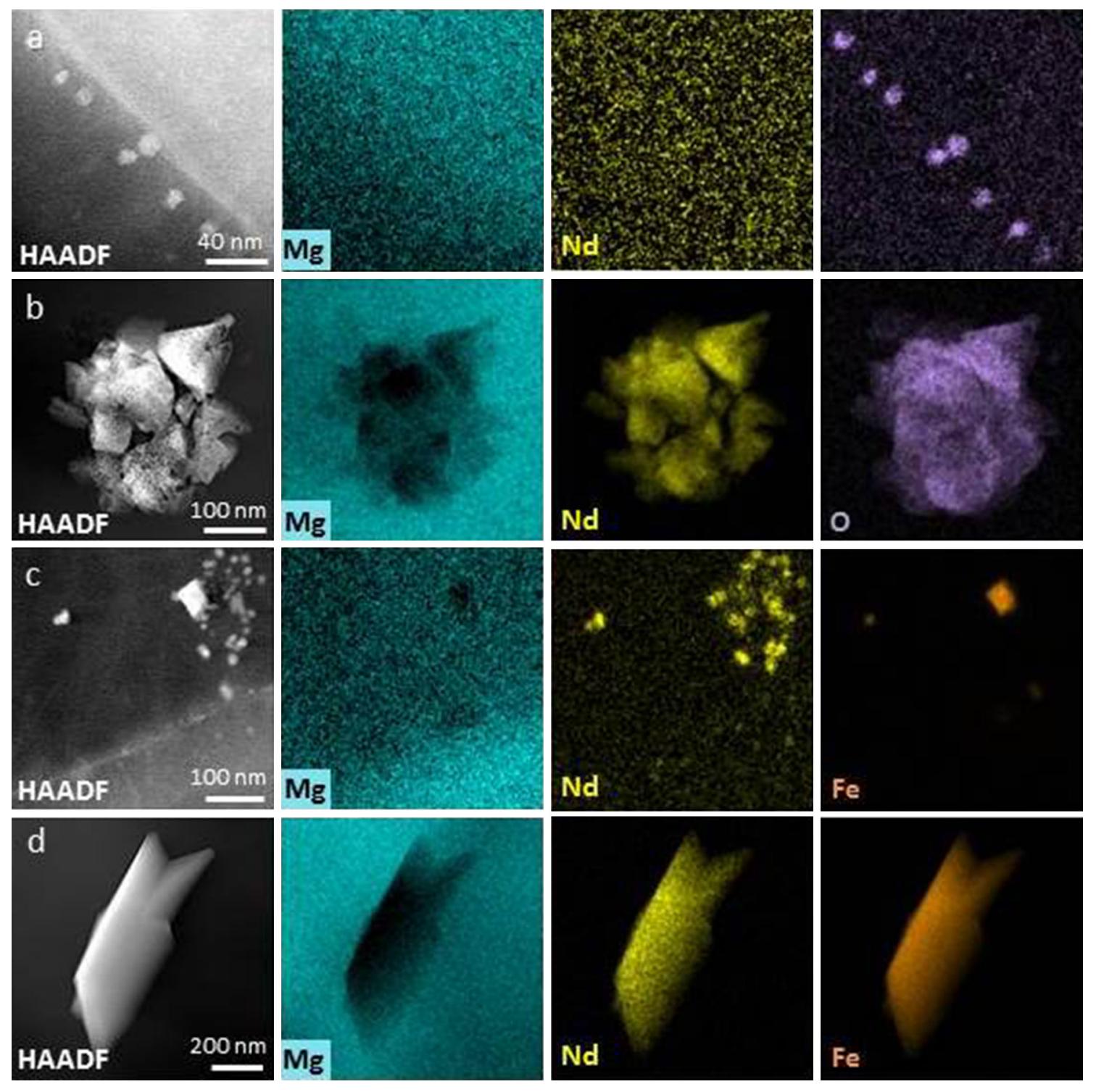

Fig. 4-Energy-dispersive X-ray spectrum imaging of Mg-0.024 at. pet $\mathrm{Nd}$ alloy. ( $a-d)$ HAADF images (right) and accompanying elemental maps (left) for $\mathrm{Mg}, \mathrm{Nd}$, and $\mathrm{O}$ or Fe. There is no evidence for $\mathrm{Nd}$ segregation on the boundary, but large $\mathrm{Nd}$ particles are observed in the sample.

accounted for. Most of the studies reported in the literature on $\mathrm{Mg}$-RE alloys have not been conducted using high-purity feedstock. Therefore, the critical RE level to produce segregation and thus the RE texture weakening effect will be dependent on the impurity content, which is often not reported. It is therefore not possible to take the critical level from one study and assume that it will be the same in another Mg-RE alloy if the impurity content is different. Although proven here for the $\mathrm{Mg}-\mathrm{Nd}$ system, this is also highly likely to be the case for other RE alloys, where low-solubility compounds of the RE and impurity elements are likely to form.

Finally, these results add further support to the idea that segregation of $\mathrm{RE}$ to grain boundaries is a necessary condition to provide the RE texture weakening effect. In the $\mathrm{Mg}-\mathrm{Y}$ alloy, where strong segregation occurred, texture weakening was seen. In the $\mathrm{Mg}-\mathrm{Nd}$ alloy where no segregation was measured, there was no texture weakening.

\section{Solute Drag Model}

The measured level of segregation on the grain boundaries can be used to provide a more accurate prediction of the solute drag effect with the CLS model. It has been shown that in the Mg-Y alloy, both Y and unexpectedly $\mathrm{Ni}$ segregation are observed on the boundary.

Figure 5 shows the calculated values of the grain boundary segregation energy $\left(\Delta G_{\mathrm{seg}}\right)$ for $\mathrm{Ni}$ and $\mathrm{Y}$ from the present results as well as for Gd using the relative compositions reported in the literature for matrix and grain boundary regions. ${ }^{[9]}$ Also shown are the lattice diffusion coefficients at $673 \mathrm{~K}\left(400{ }^{\circ} \mathrm{C}\right)$ calculated in the case of $\mathrm{Gd}$ and $\mathrm{Y}$ from the data of Das et al. ${ }^{[17]}$ and 


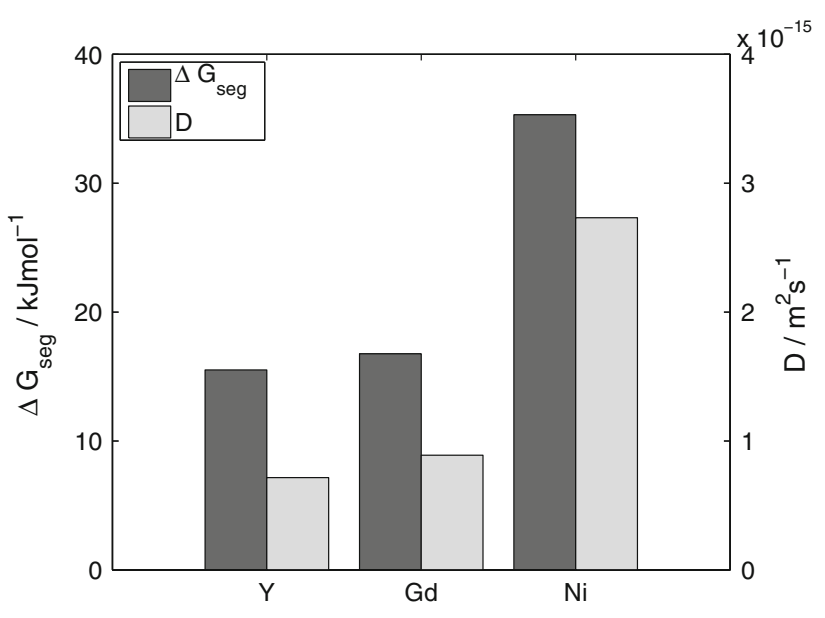

Fig. 5- Grain boundary segregation free energy change $\Delta G_{\text {seg }}$ calculated from measured grain boundary concentrations and lattice diffusion coefficients for $\mathrm{Y}, \mathrm{Nd}$, and $\mathrm{Ni}$.

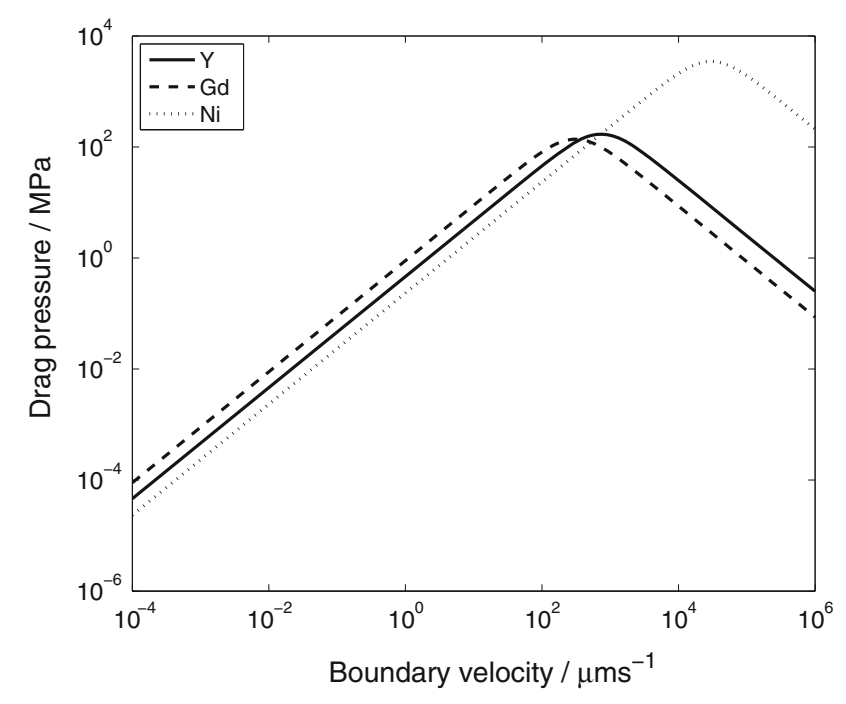

Fig. 6- Calculated solute drag pressure as a function of boundary velocity for $\mathrm{Y}, \mathrm{Gd}$, and $\mathrm{Ni}$ at $673 \mathrm{~K}\left(400{ }^{\circ} \mathrm{C}\right)$.

estimated in the case of $\mathrm{Ni}$, where no accurate measurements of diffusion coefficient in $\mathrm{Mg}$ are reported. The diffusion coefficient for $\mathrm{Ni}$ in $\mathrm{Mg}$ was estimated from the diffusion coefficient $(D)$ of $\mathrm{Ni}$ in $\mathrm{Al}$, for which measurements are available. ${ }^{[19]}$ The justification for making this empirical approximation is that the impurity diffusion coefficients for other solutes (such as $\mathrm{Zn}$ ) are found to be similar in both $\mathrm{Mg}$ and $\mathrm{Al}$, and the close coincidence of the melting point of $\mathrm{Mg}$ and $\mathrm{Al} .{ }^{[19,25]}$ For example, at $673 \mathrm{~K}\left(400{ }^{\circ} \mathrm{C}\right.$, the annealing temperature in this study), $D_{\mathrm{Zn}}$ is $1.2 \times 10^{-14} \mathrm{~m}^{-2} \mathrm{~s}^{-1}$ in $\mathrm{Al}$ and $1.9 \times 10^{-14} \mathrm{~m}^{-2} \mathrm{~s}^{-1}$ in $\mathrm{Mg}$, which is within a factor of 2. Given the approximations necessary in estimating both $\Delta G_{\text {Seg }}$ and $D$, the quantitative accuracy of the predictions is likely to be low. However, qualitatively they are still valuable in allowing the relative effect of different solutes on the drag effect to be estimated.

The values of $\Delta G_{\text {seg }}$ shown in Figure 5 can be compared with those predicted previously using the

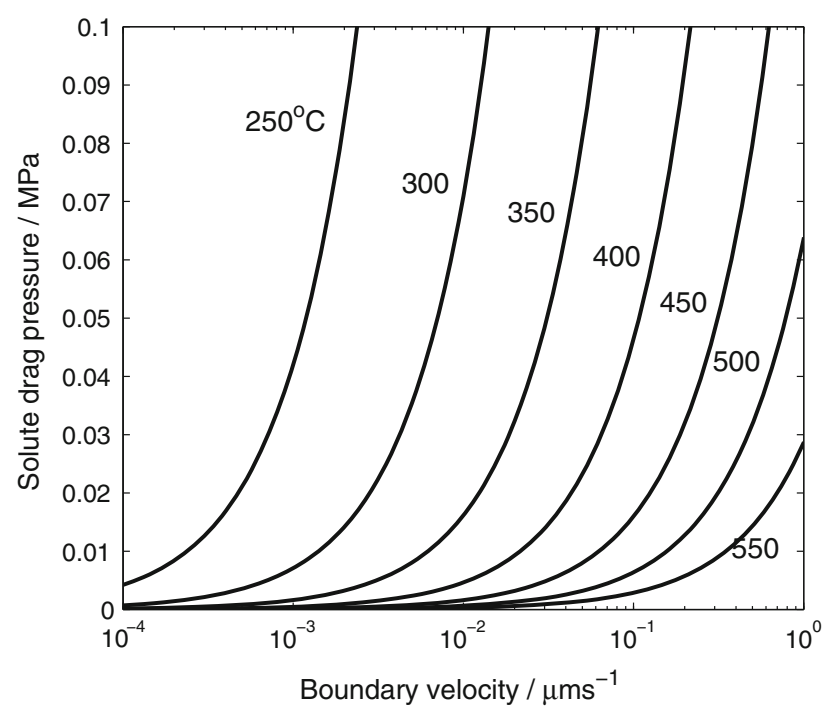

Fig. 7-Calculated solute drag pressure as a function of boundary velocity for $\mathrm{Y}$ at temperatures ranging from $523 \mathrm{~K}$ to $823 \mathrm{~K}\left(250{ }^{\circ} \mathrm{C}\right.$ to $550{ }^{\circ} \mathrm{C}$ ).

classical misfit-based model. ${ }^{[12]}$ This shows that the values of $\Delta G_{\mathrm{seg}}$ calculated on the basis of the measured boundary compositions are approximately 4 times greater than those calculated on the basis of misfit alone, i.e., the tendency to segregate is also strongly driven by other factors, including the synergistic interaction of $\mathrm{Ni}$ and $\mathrm{Y}$, as discussed. The very high level of $\mathrm{Ni}$ segregation measured produces the high $\Delta G_{\text {seg }}$ value reported in Figure 5. However, Ni is also expected to have a significantly higher diffusion coefficient in $\mathrm{Mg}$ compared to $\mathrm{Y}$ or $\mathrm{Gd}$, and these factors are in opposition in determining solute drag in the low-boundary velocity regime.

Using these values of $\Delta G_{\text {seg }}$, the CLS model has been used to predict the variation in drag pressure for the three solutes at $673 \mathrm{~K}\left(400^{\circ} \mathrm{C}\right)$ as a function of boundary velocity, and this is shown in Figure 6. This plot shows the transition between the low- and highvelocity regimes, with the peak drag pressure corresponding to the transition point. As discussed elsewhere, for recrystallization in $\mathrm{Mg}$, boundary velocities of the order of $10^{-2} \mu \mathrm{m} \mathrm{s}^{-1}$ would be expected. Figure 6 shows that this lies in the low-velocity regime, well below the transition point. For this boundary velocity, the CLS model predicts that Gd will exert a drag pressure twice that of $\mathrm{Y}$ and 5 times that of Ni.

Figure 7 shows the predicted solute drag pressure for $\mathrm{Y}$ as a function of boundary velocity over a range of temperatures typical of that for the thermomechanical processing of magnesium alloys. This plot illustrates the very strong dependence of the solute drag effect on temperature. Note that the true dependence of solute drag on temperature is likely to be even greater than predicted by this model since to perform this calculation it was assumed that the depth of the free energy well associated with grain boundaries is constant, whereas in practice it will decrease at higher temperatures due to the increased contribution from entropy, which opposes 
segregation. For example, for a boundary velocity of $10^{-2} \mu \mathrm{m} \mathrm{s}^{-1}$, there is a three-order-of-magnitude difference between the drag pressures predicted at $523 \mathrm{~K}$ and $823 \mathrm{~K}\left(250{ }^{\circ} \mathrm{C}\right.$ and $\left.550{ }^{\circ} \mathrm{C}\right)$. A drop in solute drag pressure below a critical value required to suppress dynamic recrystallization and create an RE texture effect is a plausible reason why the RE texture is not seen in $\mathrm{Mg}-\mathrm{RE}$ alloys when the deformation (e.g., extrusion) temperature exceeds a critical value. ${ }^{[6]}$

\section{CONCLUSIONS}

This study has confirmed the important role of grain boundary segregation in producing a texture change during recrystallization when $\mathrm{RE}$ additions are present. In the $\mathrm{Mg}-\mathrm{Y}$ alloy, strong segregation to grain boundaries was detected and texture strength reduced markedly on recrystallization. In the $\mathrm{Mg}-\mathrm{Nd}$ alloy, no segregation, or significant texture weakening effect, was observed after recrystallization. This is probably because the $\mathrm{Nd}$ is present in insoluble particles, both alone and with varying contents of $\mathrm{O}$ and/or $\mathrm{Fe}$ impurities, even at $\mathrm{Nd}$ concentrations previously thought to be well below the solubility limit of $\mathrm{Nd}$ in magnesium. Also observed, but unexpected, was strong segregation of impurity $\mathrm{Ni}$ to the grain boundaries.

A simple classical model has been applied to predict the solute drag effect associated with the rare-earth (RE) segregation to grain boundaries. It is demonstrated that the driving force for segregation is greater than that predicted in previous studies based on atomic size misfit alone. There is likely to be a synergistic interaction between segregated $\mathrm{Y}$ and impurity $\mathrm{Ni}$, both of which concentrate strongly on the grain boundaries. For conditions typical of those expected during thermomechanical processing of magnesium, it is predicted that Gd will have a drag effect approximately twice that of Y. The predicted strong decrease in solute drag pressure with increasing temperature may explain why RE textures are not observed in Mg-RE alloys deformed above a critical temperature.

This study provides further evidence to support the argument that segregation to grain boundaries plays a key role in enabling the texture change seen on recrystallization of dilute $\mathrm{Mg}-\mathrm{RE}$ alloys.

\section{ACKNOWLEDGMENTS}

The authors are grateful to Magnesium Elektron for provision of materials used in this study. The Engineering and Physical Sciences Research Council (EPSRC) through the Centre for Doctoral Training in Advanced Metallic Systems and LATEST2 platform Grant (EP/H020047/1) are thanked for supporting this research.

\section{OPEN ACCESS}

This article is distributed under the terms of the Creative Commons Attribution 4.0 International License (http://creativecommons.org/licenses/by/4.0/), which permits unrestricted use, distribution, and reproduction in any medium, provided you give appropriate credit to the original author(s) and the source, provide a link to the Creative Commons license, and indicate if changes were made.

\section{REFERENCES}

1. S.R. Agnew, J.W. Senn, and J.A. Horton: JOM, 2006, vol. 58, pp. 62-69.

2. J. Bohlen, M.R. Nürnberg, J.W. Senn, D. Letzig, and S.R. Agnew: Acta Mater., 2007, vol. 55, pp. 2101-22.

3. K. Hantzsche, J. Wendt, K.U. Kainer, J. Bohlen, and D. Letzig: JOM, 2009, vol. 61, pp. 38-42.

4. N. Stanford and M.R. Barnett: Mater. Sci. Eng. A, 2008, vol. 496, pp. 399-408.

5. N. Stanford: Mater. Sci. Eng. A, 2010, vol. 527, pp. 2669-77.

6. N. Stanford, G. Sha, J. Xia, S.P. Ringer, and M.R. Barnett: Scripta Mater., 2011, vol. 65, pp. 919-21.

7. J.P. Hadorn, K. Hantzsche, S.B. Yi, J. Bohlen, D. Letzig, J.A. Wollmershauser, and S.R. Agnew: Metall. Mater. Trans. A, 2012, vol. 43A, pp. 1347-62.

8. J.P. Hadorn, T.T. Sasaki, T. Nakata, T. Ohkubo, S. Kamado, and K. Hono: Scripta Mater., 2014. DOI:10.1016/j.scriptamat.2014. 08.022 .

9. M. Bugnet, A. Kula, M. Niewczas, and G.A. Botton: Acta Mater., 2014, vol. 79, pp. 66-73.

10. K. Hantzsche, J. Bohlen, J. Wendt, K. Kainer, S. Yi, and D. Letzig: Scripta Mater., 2010, vol. 63, pp. 725-30.

11. D. Griffiths: Mater. Sci. Technol., 2015. DOI:10.1179/1743284714Y. 0000000632 .

12. J.D. Robson: Metall. Mater. Trans. A, 2014, vol. 45A, pp. 3205-12.

13. J.W. Cahn: Acta Metall., 1962, vol. 10, pp. 789-98.

14. K. Lücke and H.P. Stüwe: in Recovery and Recrystallization of Metals, L. Himmel, ed., Interscience, New York, 1963, pp. 171-76.

15. F.J. Humphreys and M. Hatherly: Recrystallization and Related Annealing Phenomena, Pergamon Press, Oxford, 1996.

16. P. Gordon and R.A. Vandermeer: ASM. Ch., 1965, vol. 6, pp. 205-65.

17. S.K. Das, Y.B. Kang, T. Ha, and I. Jung: Acta Mater., 2014, vol. 71, pp. 164-75.

18. J.W. Christian: Theory of Transformations in Metals and Alloys, Pergamon Press, Oxford, 1975

19. Y. Du, Y.A. Chang, B. Huang, W. Gong, Z. Jin, H. Xu, Z. Yuan, Y. Liu, Y. He, and F.Y. Xie: Mater. Sci. Eng. A, 2003, vol. A363, pp. $140-51$.

20. D. McLean: Grain Boundaries in Metals, Oxford University Press, Oxford, 1957.

21. P. Lejček and S. Hofmann: Crit. Rev. Solid State Mater. Sci., 1995, vol. 20, pp. 1-85.

22. S.G. Kim, A. Inoue, and T. Masumoto: Mater. Trans. JIM, 1990, vol. 31, pp. 929-34.

23. A.A. Nayeb-Hashemi and J.B. Clark: Bull. Alloy Phase Diagr., 1985, vol. 6, pp. 238-44.

24. A.A. Nayeb-Hashemi, J.B. Clark, and L.J. Swartzendruber: Bull. Alloy Phase Diagr., 1985, vol. 6, pp. 235-38.

25. J. Cermák and I. Stloukal: Compos. Sci. Technol., 2008, vol. 68, pp. 417-23. 